\title{
REALIDAD Y FICCIÓN. DESDE LA AUTOPERCEPCIÓN A LA SOCIABILIZACIÓN TECNOLÓGICA: DISCURRIR HISTÓRICO
}

\author{
REALITY AND FICTION. FROM AUTORECOGNITION TO \\ TECNOLOGICAL SOCIALIZATION: HISTORICAL EVOLUTION
}

\section{AUTORES}

David Lavilla Muñoz

Profesor Doctor de la Universidad Europea de Madrid (UEM). Madrid (España) davidjose.lavilla@uem.es

\section{Rodrigo Mesonero Izquierdo}

Profesor asociado. Universidad Europea de Madrid (UEM). Madrid (España)

rodrigo.mesonero@uem.es

\section{RESUMEN}

El hombre se define como un ser racional y social. Como tal, ha tratado de entender el mundo que lo rodea definiéndolo a través de las ficciones. Todo el proceso evolutivo en los medios de comunicación ha estado orientado a hacer la comunicación más efectiva y real. Las redes sociales son el paso definitivo hasta el momento. En ellas las ficciones pueden convertirse en realidad.

\section{PALABRAS CLAVE}

Realidad - Ficción - Redes Sociales - Medios de comunicación.

\section{ABSTRACT}

Man is defined as a rational and social being. As such, he has tried to understand the world around defining it through fiction. The whole evolutionary process in the media has been designed to make communication more effective and real. Social networks are the final step so far. In them, fictions become reality. 


\section{REVISTA DE LA SEECI.}

Lavilla Muñoz, David y Mesonero Izquierdo, Rodrigo (2010): Realidad y ficción.

Desde la autopercepción a la sociabilización tecnológica: Discurrir histórico. № 22.

Julio. Año XI9. Páginas: 16-29

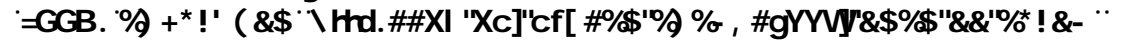

\section{KEY WORDS}

Reality - Fiction - Social Networks - Communication.

\section{ÍNDICE}

1. Introducción.

1.1 La mecánica: los inicios del intercambio lúdico.

1.2 El cable y el comienzo de la comunicación instantánea: imaginando el juego.

1.3 La guerra y el devenir de la comunicación: destruir jugando.

1.4 Sociedad en Red Social: el juego del espejo tecnológico.

2. Bibliografía.

3. Webgrafía.

\section{Introducción}

Realidad y ficción son términos inseparables. A medida que el hombre ha ido desarrollado su intelecto, ha ido creando su propio espacio, un lugar de (re)creación o juego en función a estas dos palabras, generando así el conocimiento de lo que le rodea y de sí mismo. Por tanto, el hombre es creador endógeno y exógeno. Un dios ${ }^{1}$ creador perceptivo, racional, consciente e inconsciente.

Pero antes de crear exógenamente, como dios, el hombre debe crearse a sí mismo, también como dios, porque es esto, precisamente, lo que se denominaría como autorreconocimiento, lo que diferencia al hombre del resto de seres. Este desarrollo

\footnotetext{
${ }^{1}$ LAVILLA MUÑOZ, David. La creación (I, II, III, IV, V, VI y VII). http://salademaquinas.blogia.com/ Disponible en línea. (Consultado: 20 de mayo de 2011).
} 


\section{REVISTA DE LA SEECI.}

Lavilla Muñoz, David y Mesonero Izquierdo, Rodrigo (2010): Realidad y ficción.

Desde la autopercepción a la sociabilización tecnológica: Discurrir histórico. № 22.

Julio. Año XI9. Páginas: 16-29

, 661 血

del ego lo describe Jaques Lacan en su fase del espejo ${ }^{2}$. Siguiendo al filósofo francés, el humano toma autoconciencia cuando es capaz de identificarse a sí mismo en el momento en el que ve su imagen reflejada.

Así pues, cuando el humano nace es una de las especies que llegan al mundo sin desarrollarse completamente. Necesita del cuidado adulto para sobrevivir y completar su formación. En este momento, se ve reflejado en su madre a la que toma como espejo. No es, sino una suma de partes inconexas entre sí. A través de la madre es que encuentra unidad y sentido. Entre los seis y dieciocho meses se produce el fenómeno que supone el nacimiento de la conciencia propia. Al verse reflejado frente a un espejo es capaz de reconocer que aquello que ve frente a él no es otra cosa que su propia totalidad que le define como individuo. Al principio se produce un momento de confusión, seguido de excitación al reconocerse. Ha nacido el "Ego". Ya no es una extensión de nuestra madre, sino un ser único y diferenciado del resto.

Cuando este nacimiento del ego se produjo en el hombre, nació la conciencia y la necesidad de crear y entender la realidad. Pero, como si de un doble proceso se tratara, el hombre, en una primera fase, se reconocía en los otros para encontrar lo real. No era más que a través de la repetición de rituales prototipos ${ }^{3}$ que uno discernía qué era real.

En la obra El mito del eterno retorno ${ }^{4}$, Mercieda Eliade define que

"lo real es lo sagrado; pues sólo lo sagrado es de un modo absoluto, obra eficazmente, crea y hace durar las cosas. Los innumerables actos de consagración - de los espacios, de los objetos, de los

\footnotetext{
${ }^{2}$ LACAN, Jaques (2009): Escritos 1. Siglo XXI editores. México, 2009.

${ }^{3}$ La mitificación de los prototipos históricos que han proporcionado protagonistas a las canciones épicas populares se han moldeado según un patrón ejemplar: están hechos "a imagen y semejanza" de los héroes de mitos antiguos. Todos se parecen, puesto que todos tienen un nacimiento milagroso y, además, por lo menos uno de sus padres es un dios. Al igual que en los cantos épicos tátaros y polinesios, los héroes emprenden un viaje al cielo o bien descienden a los infiernos. ELIADE, Mircea (1997): El mito del eterno retorno. Ed. Alianza/Emecé. Madrid. Pág. 47.

${ }^{4}$ Ibid: ELIADE, Mircea (1997)
} 


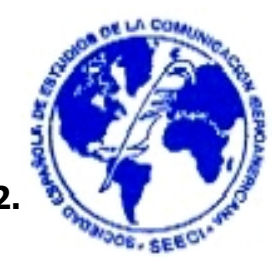

hombres, etc.- revelan la obsesión de lo real, la sed del primitivo por el ser't5.

Así, el hombre arcaico sólo encuentra la realidad en la repetición de los actos sagrados que dieron origen al mundo porque "toda actividad responsable y con una finalidad definida constituye para el mundo arcaico un ritual't.

Desde este punto de vista, se puede considerar que Platón es el que mejor recoge esta mentalidad en su obra La República ${ }^{7}$, donde apunta que lo que tomamos por real no son más que las sombras de las realidades inmutables y eternas que son las ideas ${ }^{8}$.

Es decir, para Platón la realidad reside fuera de lo tangible. Para el filósofo griego la realidad está en el mundo de las Ideas, inalcanzable por los sentidos pero sí por la ciencia. Las I deas son para Platón lo que lo sagrado para el hombre arcaico.

Por otro lado, Friedrich Nietzsche, en su obra Sobre la verdad y la mentira ${ }^{9}$, asegura que el hombre "es indiferente al conocimiento puro y sin consecuencias e incluso hostil frente a las verdades susceptibles de efectos perjudiciales o destructivos ${ }^{\prime \prime 1}$. Para Nietzsche la verdad de la naturaleza es "inaccesible e indefinible"11. Por otro

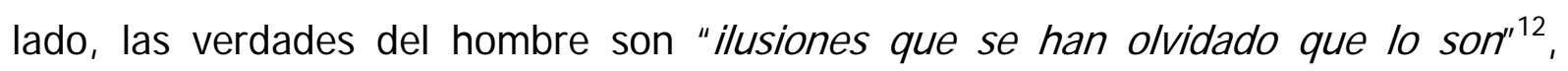
generadas a partir del lenguaje. El hombre no es capaz de comprender la esencia única de la naturaleza por lo que se conforma con crear mentiras, conceptos, que intentan atraparla. La realidad está frente a nosotros pero somos incapaces de asumirla.

\footnotetext{
${ }^{5}$ I bid: ELIADE, Mircea (1997): Pág. 20.

${ }^{6}$ Ibid: ELIADE, Mircea. (1997): Pág. 34.

${ }^{7}$ PLATÓN. La República (Tomo III, Libro VII). Centro de estudios políticos e institucionales. Madrid, 1997.

${ }^{8}$ I gual que nosotros -dije-, porque en primer lugar, ¿crees que los que están así han visto otra cosa de sí mismos o de sus compañeros sino las sombras proyectadas por el fuego sobre la parte de la caverna que está frente a ellos? (...) Entonces no hay duda - dije yo- de que los tales no tendrán por real ninguna otra cosa más que las sombras de los objetos fabricados. Platón. La República (Tomo III, Libro VII). Centro de estudios políticos e institucionales. Madrid, 1997. Pag. 2 y 3.

${ }^{9}$ NIETZSCHE, Friedrich y VAIHINGER, Hans (1996): Sobre la verdad y la mentira. Ed. Tecnos. Madrid.

10 Ibid: NIETZSCHE, Friedrich, Vaihinger, Hans. (1996) Pág. 21.

${ }^{11}$ Ibid: NIETZSCHE, Friedrich, Vaihinger, Hans. (1996): Pág. 24

12 Ibid: NIETZSCHE, Friedrich, Vaihinger, Hans. (1996) Pág. 25.
} 
Ya sea por crear prototipos míticos o por incapacidad de definir la realidad, el hombre, desde el principio de los tiempos, ha creado ficciones en la que refugiarse y encontrar su realidad.

Todo en el hombre ha sido una continua progresión en el perfeccionamiento para convertir esa ficción creada en algo que cada vez se sienta como más real. A medida que el hombre -a través de los tiempos- ha desarrollado su intelecto, ha ido creado su espacio de juego -su propio mundo- a imagen y semejanza gracias a sus sueños. A sus fantasías. A sus ilusiones. Como un dios, pues.

Y siempre ha evolucionado en la misma dirección. El arte rupestre sirvió para representar escenas o materializar visiones al humano. Más tarde, con la invención del código escrito, el ser humano hizo realidad uno de los mayores milagros conocidos en la historia del hombre, la literatura. Mediante esta manifestación artística, el individuo pudo transmitir a sus descendientes - de forma física y perecedera- su mejor legado: la imaginación de lo real.

\subsection{La mecánica: los inicios del intercambio lúdico}

La invención de la máquina a vapor (James Watt, 1769) propuso al hombre un nuevo intercambio de comunicación, casi lúdico, diferente al conocido hasta entonces: algo era capaz de realizar un trabajo que antes era elaborado por él mismo de forma manual, artesana.

De la misma forma, la velocidad en las comunicaciones se iba haciendo un hecho cada vez más necesario. El correo postal precisaba de mayor fugacidad, y los animales no eran capaces de hacer llegar los comunicados de manera rápida. 
De esta necesidad de velocidad, nació el ferrocarril (Richard Trevithik, 1802). Este veloz y colosal medio de locomoción, capaz de transportar gran cantidad de mercancías y pasajeros.

Pero no sólo el invento de ferrocarril hizo variar la comunicación humana. Con anterioridad, las mejoras en los procesos de producción agrícola - usando entre otros utensilios la sembradora mecánica (J ethro Tull, 1701) - y los avances técnicos de los procesos de producción textil, como telar mecánico (Cartwright, 1794) -, produjeron un nuevo diálogo endógeno y exógeno en el ser humano. Éste ya no se tenía que entender sólo con personas. Los aparatos formaban parte de su nueva realidad, la mecánica. Más allá de la comunicación interpersonal, había nacido la comunicación hombre-máquina, un nuevo estrato de lo real.

Si bien es cierto que el lenguaje binario tardaría cientos de años en llegar, el hombre ya estaba utilizando una nueva forma de comunicarse consigo mismo, con los demás y con los propios utensilios mecánicos que había creado.

Por este motivo, su conducta se estaba modificando de manera ostensible $y$, por consiguiente, también lo hacía su lenguaje escrito, hablado y gestual. El cerebro humano estaba experimentando un cambio ante estos hechos. Los caminos neuronales se hacían diferentes, porque los estímulos y las respuestas hacia ellos eran distintos. La comunicación ya no era estrictamente interpersonal, ya que dependía de nuevos canales de transmisión de mensajes.

\subsection{El cable y el comienzo de la comunicación instantánea: imaginando el juego}

Uno de los inventos que cambiaron radicalmente el concepto de diálogo fue el telégrafo. Con él llegó la comunicación instantánea desde dos puntos geográficamente muy alejados. Samuel Morse (1835), a través de un nuevo medio y 
un nuevo lenguaje, creo una forma diferente de relación entre el hombre, la información y la comunicación. Porque a partir de ese momento histórico surgió una nueva forma de comunicación, una nueva forma de interactuación.

El ser humano ya no necesitaba estar presente para recibir un mensaje de manera instantánea, ipso facto. Desde cualquier lugar interconectado por tendidos de cobre, una persona podía enviar o recibir informaciones. Con lo que la comunicación presencial instantánea no requería del gesto y sí del verbo, aunque, eso sí, codificado. Y este hecho no estaba exento de inconvenientes, ya que las imperfecciones del medio y la manera de transmitir mensajes producían algunas confusiones (ruidos) a los emisores y destinatarios de las informaciones que se difundían.

El mayor inconveniente era, como se ha citado, la no observación del gesto -ni de forma mecánica y mucho menos física- del emisor. Los mensajes quedaban condicionados a la palabra en forma de código y a las interpretaciones que el receptor extraía de un lenguaje. La realidad tornó en virtualidad, o mejor dicho, lo rea/ también era aquello que habitaba en lo virtual.

Es justo decir que a partir de este momento existe un antes y un después en cuanto a la forma de emitir y recibir mensajes. Comienza una revolución en el concepto de comunicación. Pero también hay que dejar constancia del controvertido surgimiento de una manera distinta de entender la realidad. Una realidad también condicionada por los principios del liberalismo económico, con sus ventajas e inconvenientes. Y precisamente uno de ellos era el ahorro del código, además de los problemas técnicos que surgían a la hora de su emisión. Este hecho fue el desencadenante de la Teoría matemática de la Información de Claude Shannon Elwood y Warren Weaver, que no se desarrolló hasta el Siglo $\mathrm{XX}^{13}$.

\footnotetext{
${ }^{13}$ A mediados del siglo XX Shannon y Weaver, ambos norteamericanos, proponen la Teoría Matemática de la Información - 0 de la comunicación- (TI) cuyo es explícitamente instrumental: lograr la máxima economía de tiempo, energía y dinero en el diseño de señales y canales técnicos de transmisión. [...]. El propio Weaver (1977) circunscribe sus preocupaciones a los problemas
} 


\subsection{La guerra y el discurrir de la comunicación: destruir jugando}

Toda vez que el Telégrafo se iba instaurando de manera inminente en la Sociedad, iban surgiendo nuevas inquietudes para que la interactuación entre los hombres fuera más rápida y efectiva.

Pero esta evolución ya no provenía de la necesidad de entender la realidad sino de la necesidad de poseerla, controlarla y manipularla. ${ }^{14}$

En la Primera Guerra Mundial (1914-18) murieron más de 700.000 personas, pero, una vez terminado el conflicto, se instauraron en la sociedad definitivamente avances en la comunicación tan importantes como el teléfono o la radio. Lo mismo sucedió en la Segunda Gran Guerra (1941-45), eso sí, esta con más víctimas mortales -alrededor de 50 millones-, pero, a cambio, se asentaron dos poderosos massmedia: el cine y la televisión. Asimismo, en estos dos grandes conflictos, la prensa escrita iba adquiriendo más recursos técnicos con el firme objetivo de persuadir con sus mensajes a más individuos.

técnicos de transmisión, y excluye consecuentemente los problemas semánticos: qué significados se transmiten, e influenciales: cómo afecta el mensaje al receptor.

Ref.: Abril, Gonzalo (1997): Teoría General de la Información. Datos, relatos y ritos. Cátedra. Madrid. P-16.

${ }^{14}$ La comunicación, para lo que sirve, en primer lugar, es para hacer la guerra. Pero, fuera del periodo de hostilidades, que suscitan la abundancia de los análisis e incluso su aislamiento al servio de los ejércitos, la guerra se ha constituido, tradicionalmente, en zona ciega a cerca de la comunicación. En confinamiento de comunicación en la industria del entretenimiento en tiempo de paz no es el último en hacer inaudible el discurso sobre la relación- comunicación-guerra. Los manuales de guerra psicológica para las fuerzas armadas dicen más sobre el tema que en la mayoría de los textos en los que los futuros profesionales de la comunicación aprenden los rudimentos de su oficio.

Ahora bien, la guerra y su lógica son componentes esenciales de la historia de la comunicación, de sus doctrinas y de sus teorías, así como de los usos que de ellas hayan podido hacerse. Esto se ha comprobado desde el alba del telégrafo y de la fotografía. Y la jurisprudencia sentada con motivo de la Guerra de crimen, hace cerca de ciento cuarenta años, a propósito de la puesta en imagen de la guerra es la primera de una larga serie de decisiones que desembocaron, en enero de 1991, en el control total de la información por parte de las autoridades militares. La primera experiencia masiva de que la teoría de la comunicación ha extraído sus hipótesis a cerca de la gestión de la opinión de las grandes multitudes es la Primera guerra Mundial, un conflicto total que iría afectando a más y más gente. Será entonces cuando despegue la noción de propaganda que, luego, con ocasión del segundo conflicto, se metamorfoseará en la guerra psicológica. No sin antes haber transitado por la doctrina del partido nacional-socialista nazi y por el agitprop del joven poder soviético y del Komintern. Extremadamente simbólico es el hecho de que, en plena Guerra Fría, allá por los años cincuenta, vea la luz en los Estados Unidos, el primer intento de construcción, al abrigo de la sociología empírica, de una disciplina denominada comunicación internacional.

Ref: MATTELART, Armand (1993): La comunicación-mundo. Historia de las ideas y de las estrategias. FUNDESCO. Madrid. Págs. 13-14. 
De igual forma genocida, el hombre, en la Guerra Fría, se inventó la herramienta Internet y, a poco tardar, en la I Guerra del Golfo, la telefonía móvil entraba en la escena del nuevo orden de la comunicación social para llegar a su auge de desarrollo en la II Guerra del Golfo, con la telefonía móvil de Tercera Generación (3-G) y la tecnología láser.

Si la literatura, la pintura y la fotografía fueron las primeras herramientas para desarrollar la imaginación y crear nuevos universos; el videojuego, Internet y la telefonía móvil son los instrumentos de los que actualmente se sirve esta nueva era de la comunicación y de la información para generar frenesíes, ilusiones, ficciones, sueños.

Así pues, de generación en generación, realidad y ficción se han hecho inseparables compañeras para comunicar sucesos y sentimientos, con el fin de causar emociones, conocimiento y crear realidad.

¿Pero acaso los seres vivos son los únicos que pueden producirlas?

La Inteligencia Artificial, exenta todavía de sensaciones, provoca un sinfín de emociones $^{15}$ al cerebro humano. Las computadoras, creadas por la "divina" mano del hombre -y portadoras de la I.A- se están apoderando de los afectos en la sociedad del siglo XXI 0, por lo menos, están generando nuevas pautas de conducta produciendo, ante nuevos estímulos, nuevas respuestas.

En este periodo histórico -y sin duda en los venideros-, las máquinas están adquiriendo un papel protagonista en el comportamiento cognitivo y conductual del ser humano. Los ordenadores, Internet, la telefonía móvil, el cine de animación y los videojuegos son claros ejemplos de esta afirmación que, aunque parezca reciente, viene ya de lejos.

15 LAVILLA MUÑOZ, David (2007): “Las emocionantes máquinas se emocionan: reflexiones paranoicas de un «hombrecomputadora»" en Orbis Tertius: Revista de pensamiento y análisis de la Fundación SEK. №. 1. Págs. 9-74. 


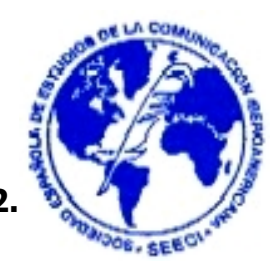

Los inicios teóricos de la interactuación entre el ser humano y la máquina se remontan al año 1942, coincidiendo con un congreso sobre inhibición cerebral realizado en la ciudad de Nueva York entre técnicos expertos en mecanismos de control y fisiólogos. Es seis años más tarde, en 1948, cuando Norbert Wiener publicó en París su obra Cybernetics ${ }^{16}$ y definitivamente surgió la necesidad de crear una nueva ciencia para estudiar los efectos que producían las máquinas en la comunicación y en la información, la cibernética.

Este campo de conocimiento pretende dar respuesta a un nuevo y emergente orden social. A obtener una catalogación de máquinas -capaces en muchos casos de reaccionar con más exactitud y urgencia que los seres vivos- en el terreno de la comunicación y de la información. Y a dar explicaciones rigurosas de los efectos que producen los cerebros electrónicos -creados por mentes naturales, las humanas- en la economía mundial.

\subsection{Sociedad en Red Social: el juego del espejo tecnológico}

Este nuevo siglo se difiere de todos los demás anteriores porque con estos nuevos soportes multimedia la imaginación va más allá de las palabras, de los sonidos o de las imágenes. El diálogo hombre-hombre, hombre-máquina y máquina-máquina se culmina con una máxima interactuación por parte de los emisores y receptores.

Los soportes, que gozan de mayor sofisticación, otorgan a los mensajes mayor velocidad a la información ${ }^{17}$, con todas las ventajas e inconvenientes que ello conlleva, por lo que los sujetos pueden llegar a interactuar en un espacio-tiempo alejado pero, a su vez, cercano.

\footnotetext{
${ }^{16}$ Norbert Wiener relaciona a la Cibernética con la teoría de la información. Actualmente esta teoría constituye una rama de la matemática binaria, booleana o lógica. Habla del mensaje como conjunto de elementos de percepción que determinan las reacciones humanas ante estímulos, que consisten en signos naturales o señales y que se adaptan a un código. Mediante una forma logarítmica se mide en bits la cantidad de información intrínseca en un mensaje. Las máquinas que intervienen en los procesos de datos estarían incluidas en las siguientes categorías: reacción del medio según un programa previo, reacción imprevisible (sometida a leyes ya conocidas) y reacción totalmente imprevisible.

Passim: WIENER, Norbert (1985): Cibernética. Tusquets editores. Barcelona.

17 "Existe la ilusión de una velocidad salvadora; la ilusión de que el acercamiento exagerado entre poblaciones no va a atraer consigo conflictos sino amor, que hay que amar al que está lejos como a sí mismo". Virilio, Paul (1997): La política de lo peor. Cátedra. Madrid. P-22.
} 
A cientos de miles de kilómetros, dos personas pueden establecer una diálogo rompiendo las barreras de la lógica y hasta incluso de la física, puesto que las emociones pueden viajar a través de las autopistas de la información sin necesidad de que los protagonistas de las acciones estén presentes. $Y$ se viaja con los cinco sentidos (vista, oído, gusto, tacto y olfato) y con las sensaciones que éstos reportan al ser humano ${ }^{18}$.

Es cierto que las evocaciones también suceden en los siete artes (pintura, escultura, arquitectura, literatura, música, danza y cine), pero con la salvedad de que, gracias a las nuevas tecnologías, existe retroalimentación instantánea del mensaje. Hoy un maestro de cualquier arte, si se conecta a Internet para exhibir una de sus obras, puede ser susceptible de réplica inmediata desde cualquier parte del planeta y en cualquiera franja horaria. $Y$ eso es democracia. Porque cada individuo tiene autoridad para ofrecer una opinión.

Y así viajan en libertad las emociones. Y circulan por las ondas o los cables los afectos del ser humano en forma de amor y de odio; de sexo y de castidad; de violencia y de tolerancia; de codicia y de caridad; de filantropía y de misantropía.

Y de mentira o de verdad, de ficción o de realidad, se expresan los sentimientos y realidades del ser humano desde un videojuego, desde un Chat, desde una videoconferencia o desde las tres cosas a la vez.

Esa realidad tiene lugar en el ciberespacio que, "por ser virtual carece de extensión y ubicación física"19.

\footnotetext{
${ }^{18}$ Los seres humanos están dotados de órganos sensoriales, que les permiten percibir la realidad: ven, oyen, sienten, huelen y saborean. De esta manera viven sus experiencias en el mundo. Los estímulos, que afectan a los órganos sensoriales desde el exterior, son transformados por éstos últimos, convirtiéndolos en imágenes, sensaciones, olores y sabores. Sin embargo estos productos de nuestra actividad sensorial no son el mundo mismo, sino sólo mapas de este mundo gracias a los cuales nos podemos orientar en él, y de los que hacemos la base de nuestra manera de actuar.

Ref.: MOHL, Alexa (2004): El aprendiz de Brujo //: PNL (Programación Neurolingüística). Sirio. Barcelona. P-15.

${ }^{19}$ GUBERN, Román (2010): La metamorfosis de la lectura. Ed. Anagrama. Barcelona. Pág. 98.
} 
Las Redes Sociales $^{20}$ suponen el último paso hasta el momento en lo que refiere a la comunicación entre individuos. A través de Facebook, Twitter o Second life podemos establecer relaciones sociales con gente que conocemos en persona o crear nuevas con individuos que nunca hemos conocido físicamente. $Y$ estas relaciones las tomamos como verdaderas. De estos contactos llegan a surgir incluso matrimonios.

El mundo inalcanzable de las Ideas de Platón y la realidad única e ininteligible de Nietzsche se dan la mano en el ciberespacio ya que en él no se puede alcanzar a discernir qué es real y qué es ficción. Es imposible definir qué es verdad. Cada persona real crea su propio perfil en Facebook como también puede hacerlo cada personaje de ficción.

Cuando alguien crea un perfil en una red social, no vuelca toda su información vital. La persona tiende a seleccionar aquellos datos, fotos o comentarios, que dan a conocer la parte de ella que más le interesa. Si alguien busca novia en una red social, en ella pondrá las fotos en las que salga más favorecido. Si, por otro lado, busca trabajo, subirá fotos en las que dé el perfil profesional que requiere. En ningún caso, nadie subirá información que la avergüence como persona o no proyecte la imagen que uno quiere crear consciente $o$ inconscientemente.

En ficción no es muy distinto. La serie de Telecinco La pecera de Eva ${ }^{21}$ tiene una página en Facebook $^{22}$ en la que Eva, una psicóloga de instituto, escribe sus sentimientos y se comunica con sus seguidores sobre lo que ha pasado en los capítulos anteriores. Los espectadores-amigos sienten empatía con Eva. La consuelan cuando está deprimida y ríen con ella cuando está feliz. Cuando la serie se

\footnotetext{
${ }^{20}$ Describe todas aquellas herramientas diseñadas para la creación de espacios que promuevan o faciliten la conformación de comunidades e instancias de intercambio social.

El usuario de la "nueva" Internet cuenta con distintos dispositivos y herramientas para participar colectivamente con sus semejantes, pero de manera virtual. (...) La popularidad de estas tecnologías, que contribuyen a reforzar las redes sociales, ha ido a la par de un aumento en los niveles de intercambios de contenidos a través de la Red. Esto ha hecho de la Internet un medio más social para consumir información y trabajar, pero también para comunicarse, entenderse y compartir.

RODRÍGUEZ FERNÁNDEZ, Óscar; BRAVO DE PABLO, Sagrario y TRONCOSO EGEA, Roberto (2009): Facebook, aplicaciones profesionales y de empresa. Anaya. Madrid. Pág. 33.

${ }^{21}$ Isla Producciones, estreno 10 de enero de 2010.

22 www.facebook.com/lapeceradeeva
} 
interrumpe porque termina una temporada, el muro de Eva se llena de mensajes echándola de menos.

No son personas sino jugadores dentro del espejo los que están en contacto. La Eva que habla en Facebook no existe, no es más que la creación de un guionista, un dios. El espectador-amigo que interactúa con ella tampoco existe, no es más que su propia creación.

¿Acaso esto no es la perfecta fusión entre realidad y ficción?

Quizá sólo Dios sabe.

\section{Bibliografía}

ABRIL, Gonzalo (1997): Teoría General de la Información. Datos, relatos y ritos. Cátedra. Madrid.

ELIADE, Mircea (1997): El mito del eterno retorno. Ed. Alianza/Emecé. Madrid.

GUBERN, Román (2010): La metamorfosis de la lectura. Ed. Anagrama. Barcelona.

LACAN, Jaques (2009): Escritos 1. Siglo XXI editores. México. 
LAVILLA MUÑOZ, David. La creación (I, II, III, IV, V, VI y VII). http://salademaquinas.blogia.com/ Disponible en línea. (Consultado: 20 de mayo de 2011).

LAVILLA MUÑOZ, David. "Las emocionantes máquinas se emocionan: reflexiones paranoicas de un "hombre-computadora»" en Orbis Tertius: Revista de pensamiento y análisis de la Fundación SEK. №. 1. 2007.

MATTELART, Armand (1993): La comunicación-mundo. Historia de las ideas y de las estrategias. Fundesco. Madrid.

MOHL, Alexa (2004): El aprendiz de Brujo II: PNL (Programación Neurolingüística). Sirio. Barcelona.

NIETZSCHE, Friedrich y VAIHINGER, Hans (1996): Sobre la verdad y la mentira. Ed. Tecnos. Madrid.

PLATÓN (1997): La República (Tomo III, Libro VII). Centro de estudios políticos e institucionales. Madrid.

RODRíGUEZ FERNÁNDEZ, Óscar; BRAVO DE PABLO, Sagrario y TRONCOSO EGEA, Roberto (2009): Facebook, aplicaciones profesionales y de empresa. Anaya. Madrid.

VIRILIO, Paul (1997): La política de lo peor. Cátedra. Madrid.

WIENER, Norbert (1985): Cibernética. Tusquets editores. Barcelona.

\section{Webgrafía}

www.facebook.com/lapeceradeeva (Consultado el 18 de mayo de 2011) 